BULLETIN Bulletin hispanique

HispaniQuE Université Michel de Montaigne Bordeaux

113-1 | 2011

Actes de 2 colloques

\title{
Los libros franceses en las librerías de La Habana en 1826
}

Jean-Marc Buiguès

\section{(2) OpenEdition}

\section{Journals}

Edición electrónica

URL: http://journals.openedition.org/bulletinhispanique/1553

DOI: 10.4000/bulletinhispanique.1553

ISSN: 1775-3821

Editor

Presses universitaires de Bordeaux

Edición impresa

Fecha de publicación: 1 junio 2011

Paginación: 485-516

ISBN: 978-2-86781-740-3

ISSN: 0007-4640

Referencia electrónica

Jean-Marc Buiguès, « Los libros franceses en las librerías de La Habana en 1826 », Bulletin hispanique [En línea], 113-1 | 2011, Publicado el 01 junio 2014, consultado el 21 abril 2019. URL : http://

journals.openedition.org/bulletinhispanique/1553; DOI : 10.4000/bulletinhispanique.1553

Este documento fue generado automáticamente el 21 abril 2019.

Tous droits réservés 


\title{
Los libros franceses en las librerías de La Habana en 1826
}

\author{
Jean-Marc Buiguès
}

1 Resulta siempre difícil conocer de manera completa y pormenorizada la oferta de impresos de una ciudad del Antiguo Régimen en un momento determinado. Por lo general el investigador afortunado encuentra el inventario de alguna que otra librería pero muy pocas veces los de todas las librerías de la ciudad. Tiene que ocurrir algo excepcional para que se elaboren inventarios sistemáticos: es el caso muy conocido, por ejemplo, de la expulsión de los jesuitas en 1767. A raíz de la Real Orden, en todos los colegios de la Compañía se elaboran inventarios de bienes y en particular inventarios de sus libros. Bernabé Bartolomé Martínez estableció un listado de estos inventarios que hoy día todavía se conservan ${ }^{1}$. Algo muy parecido pasó en La Habana en 1826 cuando el Capitán General de Cuba, Francisco Dionisio Vives, ordenó que cada librero estableciera un inventario de su librería. Sin duda, la orden se relacionaría con los intentos de rebelión ${ }^{2}$, el ambiente independentista y los movimientos libertadores del continente americano o la penetración de las ideas francesas de la Revolución o incluso del Imperio. Quizás también más llanamente el control se hizo por motivos de censura moral y política como permite intuirlo una lista de obras censuradas que acompaña los inventarios conservados en el Archivo General de Indias. Este documento menciona diez librerías que podría ser el número total de las que existían en La Habana en aquellos años: la de « $\mathrm{D}^{\mathrm{n}}$ Pascual Mendoza» ${ }^{3}$ la de la "Ymprenta de Gobierno y Capitanía General», la «Libreria de la Minerva», la de «Palmer e hijo», la de « $\mathrm{D}^{\mathrm{n}}$ Ramon Martinez», la «Libreria de papel sellado», la «Libreria de Petit», la de la "Calle de mercaderes n 8», la «Libreria de Cova» y la «Libreria de Ramos». Sin embargo, la red de difusión del impreso era más extensa con buhoneros, puestos de venta al aire libre, imprentas, porterías de conventos o incluso las casas de los propios autores.

2 Según el Censo de 1827, la población del municipio era de 94023 vecinos de los cuales 46 621 eran blancos y 22830 esclavos. En el casco antiguo, en el recinto intramuros, vivían 39 980 almas. Si calculamos la relación entre el número de librerías y el de habitantes, para 
el total de la población hay una librería por 9402 habitantes, si lo hacemos sobre la base de los blancos, una por 466, sobre la de población libre una por 711, y sobre la base de los habitantes intramuros el resultado es de una por 399 habitantes. Se pueden comparar estas medias con las que conocemos para París en 1821 donde según el estudio de MarieClaire Boscq ${ }^{4}$ existían 435 librerías, o sea una librería por 1600 habitantes. Si la cifra de diez librerías podía en un primer momento parecer débil, al relacionarla con la población y al compararla con París, una de las capitales mejor provista en librerías, la situación de La Habana ya no parece tan deficiente. También parece idéntica la relación entre el número de habitantes y el número de librerías con la de otra gran capital americana, México que en 1824 con una población entre 150000 y 160000 habitantes ${ }^{5}$ contaba con una quincena de librerías ${ }^{6}$. La relación en La Habana es de una librería por 9402 habitantes, en México de una por 10000.

Poco sabemos de los libreros habaneros a principio del siglo XIX. Ambrosio Fornet en su magnífico estudio -El libro en $\mathrm{Cuba}^{7}$ - menciona a algunos de ellos por las relaciones que tuvieron con la edición cubana. El fundador de la librería Palmer e hijo fue Pedro Nolasco Palmer, «un ex sargento del ejército, incapacitado físicamente para realizar trabajos pesados $»^{8}$, que instaló una imprenta en La Habana hacia 17919: Ambrosio Fornet lo considera como un "caso marginal» dentro del pequeño mundo de los impresores habaneros que por lo general solían gozar de una "posición desahogada» ${ }^{10}$. Sin embargo, parece que con el paso del tiempo, Palmer consiguió abrir una librería que en 1826 dirigía con su hijo y que figuraba entre las tres más importantes de La Habana, junto con las de Cova y de Ramos, dos libreros también evocados par Ambrosio Fornet. A Nicolás Ramos lo define como a un «sagaz librero» que encargó a la Imprenta del Gobierno la edición de $E l$ Conde de Alarcos de José Jacinto Milanés ${ }^{11} \mathrm{y}$ a José Cova lo menciona por vender las dos ediciones de los poemas de José María Heredia publicadas en Nueva York en 1832 y en Toluca, México, en 1832.

Desafortunadamente, entre los documentos conservados faltan las listas de dos librerías: la de Dn Ramón Martínez y la del papel sellado lo que no impide que los inventarios permitan añadir algunos datos complementarios sobre el comercio habanero del libro. Cada lista viene firmada y fechada por el librero y dueño de la tienda -caso de José de la Cova, de Pascual Mendoza, de Nicolás Ramos, de Pedro Nolasco Palmer e Hijo, de Juan Bergeon (sita calle de Mercaderes) y de José Ramón Petit- o el encargado de la librería: Juan Manuel de Arazoza ${ }^{12}$ para la "Ymprenta de Gobierno» y Lorenzo Gaylan para la librería de Minerva. Notemos que dos de estos libreros -Bergeon y Petit- llevan apellidos de origen francés. Los libreros se apresuraron a cumplir la orden del 16 de abril: la más rápida fue la propia Ymprenta del Gobierno que entregó su lista el 18 de abril, la Librería de Petit lo hizo el 19, la de Ramos el 21, las de la Minerva y de Cova el 22 y la última fue la de Palmer e hijo el 24 del mismo mes.

5 Los datos que proporcionan los documentos permiten localizar las librerías con la excepción del «Almacen de Pascual Mendoza». En la plaza de armas y frente a la Capitanía General ${ }^{13}$ se ubicaba la librería de Minerva. La librería de Petit sita en la «accesoria de la casa ${ }^{\circ} 1$ calle de lo Empedrado, frente a la pescadería» distaba una manzana de la Plaza de Armas. Tampoco quedaba muy lejos de la Plaza de Armas la librería del Papel sellado ${ }^{14}$ que estaba en un edificio que hacía esquina entre la calle de Mercaderes y la Plazuela de Santo Domingo ${ }^{15}$. En cuanto a la librería de Ramos el documento indica que se ubicaba en «la Esquina del Boquete». Sin duda estaría en la plaza de la catedral que los moradores llamaban plaza de la ciénaga porque las aguas del primer acueducto que tuvo la ciudad, la 
«zanja real» desaguaba en un boquete abierto en un muro de la plaza, en el actual Callejón del Chorro.

6 El segundo grupo se situaba en un cuadrilátero cuyo centro era la Plaza Vieja y que configuraban las calles de la Muralla, de San Ignacio y de Mercaderes. La librería de Cova estaba en el $n^{\circ} 14$ de la calle de la Muralla, la de Pedro Nolasco Palmer e Hijo en el n 5 de la calle de San Ignacio y la de Juan Bergeon en la calle de Mercaderes $n^{\circ}$ 8. La «Ymprenta del Gobierno y Capitanía General» bien descrita por Villaverde en los años treinta como «una casa de zaguán, con dos ventanas de espejo», estaba frente a la Plaza Vieja después de los portales del Rosario ${ }^{16}$.

\section{La censura: libros prohibidos de «moral corrompidísima ${ }^{17}$ »}

7 En un documento aparte se mencionan las librerías habaneras con indicación de las que tienen obras prohibidas por la Real Orden que se publicó en «los Diarios de La Habana» ${ }^{18}$. Cuatro librerías no poseen obra alguna de las mencionadas por la Real Orden : la de « $\mathrm{D}^{\mathrm{n}}$ Pascual Mendoza», la (como era de esperar) de la «Ymprenta de Gobierno», la «Libreria de la Minerva» y la «Libreria de Ramos». Para las demás librerías, el documento establece una lista de 25 obras prohibidas y en algunos casos incluso justifica su presencia con distintos comentarios.

8 La librería de Palmer e hijo tiene cuatro obras mencionadas por la Real orden: «La Religiosa en soledad ${ }^{19}$ », «La Religiosa poema», las «Obras de Sta Teresa» y la «Vida de Sta Teresa» con el comentario siguiente «La $\mathrm{R}^{1}$ Orden hace mencion de estos titulos». Sin duda detrás de estos títulos aparentemente religiosos se ocultan obras críticas o libertinas: la literatura libertina francesa del siglo XVIII ofrece toda una serie de ejemplos (La Religieuse de Diderot o La religieuse en chemise del abad Du Prat).

La librería de « $\mathrm{D}^{\mathrm{n}}$ Ramon Martinez» tiene una obra de «moral muy corrompida» según reza el documento: «El arte de amar $\mathrm{p}^{\mathrm{r}}$ Ovidio». Obra siempre sospechosa para la Inquisición como por ejemplo lo evidencia Olga Portuondo Zúñiga que indica que en Santiago de Cuba «El Arte de Amar de Ovidio y cinco ejemplares de La Vida del Caballero Tau Blas, tenidos por irreligiosos, eran conducidos al tribunal de la Inquisición para su revisión ante el canónigo doctor Miguel de Herrera y Cangas, comisario del Santo Oficio, y su notario familiar Francisco Álvarez» ${ }^{20}$.

10 La librería de «papel sellado» tiene dos obras mencionadas por la $\mathrm{R}^{1}$ Orden : «El Eusebio $\mathrm{p}^{\mathrm{r}}$ Montegon» y la «Vida de $\mathrm{S}^{\mathrm{n}}$ Fernando». El Eusebio de Pedro Montengón y Paret (1745-1824), el Rousseau español, es una extensa novela educativa en cuatro partes de cinco libros publicados de 1786 a 1788 y condenada por la Inquisición en 1799, lo que dio lugar a la publicación de una edición enmendada en 1807-1808. Fue obra de extensa difusión puesto que unos 70.000 ejemplares se vendieron en el siglo XVIII. En cuanto a la «Vida de Sn Fernando» tiene que ser otro título religioso utilizado para ocultar el verdadero contenido de la obra. También pertenecientes a esta librería son la «Europa y America comparadas» obra que el documento califica de «Deprad. q tiende a la sedición» y «Sor Ines» tachada de "sospechosa». La primera podría ser L'Europe et l'Amérique comparée de M. Drouyn de Bercy ${ }^{21}$, colono y propietario en Santo Domingo, que fue oficial Teniente Coronel del Estado Mayo provisional del Ejército francés durante la expedición de Santo Domingo (1801-1803) dirigida por el general Leclerc. La obra se publicó en París en 1818 y 
según indica la portada se vendía «Chez ROSA, Libraire, grande Cour du Palais-Royal. A Londres, chez TREUÏTEL et WURTZ. A Bruxelles, chez LECHARLIER, Libraire». La lectura de la obra no revela claramente esta tendencia «a la sedición» de no serla cuando intenta demostrar que las colonias valen tanto como las metrópolis. La «sospechosa» Sor Inés corresponde a lo ya señalado anteriormente sobre los títulos falsamente religiosos.

En la librería de Petit, se mencionan el «Codigo penal del Imperio frances ${ }^{22}$ », «La Religiosa instruida» $\mathrm{y}$ «La Religiosa mortificada», éstas dos últimas obras «por lo qe dice la $\mathrm{R}^{1}$ Orden sobre este título». La segunda -La religiosa instruida- podría ser la obra de Antonio Arbiol y Díez (1651-1726), el famoso predicador aragonés cuyas obras estaban en casi todas las bibliotecas dieciochescas o la obra con el mismo título La religiosa instruida y dirigida en todos los estados de la vida, con diálogos familiares... escrita en francés por un Religioso Carmelita Descalzo, y traducida al castellano por el Padre Fray Joseph Quiles ${ }^{23}$. La tercera es obra de otro franciscano, como Arbiol, Manuel de Espinosa -La religiosa mortificada: Explicación del cuadro que la presenta con sus inscripciones tomadas de la Sagrada Escritura a que se añade el Manual del Alma Religiosa...- publicada en Madrid en 1799 por Pedro Julián Pereyra. Si la prohibición de los códigos napoleónicos forma parte de la lucha contra las penetración de las ideas francesas, las demás obras, si se trata de las identificadas, son obras de pura ortodoxia y las razones de su censura resultan difíciles de explicar.

La librería de Juan Bergeon es la que reúne el mayor número de obras prohibidas con un total de nueve títulos. Empieza el listado por dos obras «de moral corrompidisima»: «Los Barones de Felseheim» $\mathrm{y}$ «Mi Tio Tomas». Los Barons de Felsheim (1798) y Mon oncle Thomas (1802) son dos novelas de Charles-Antoine-Guillaume Pigault de l'Épinoy, apodado Pigault-Lebrun (1753-1835) famoso novelista y dramaturgo francés. Existe una traducción española de la segunda obra ${ }^{24}$. En algunas ediciones venían grabados con escenas de quid pro quo amoroso entre dos hombres lo que podría justificar la censura o quizás también por ser Pigault-Lebrun el autor de Le Citateur (1803), obra en la que ofrece una selección de citas contre la religión cristiana, muchas de ellas de Voltaire ${ }^{25}$. Las temáticas franmasonería ${ }^{26}$ y constitucionalismo- de las dos obras siguientes - «Cuaderno de recepcion masonica» $\mathrm{y}$ «Reflexiones politicas constitu-cionales»- constituyen obviamente objetos de censura: a partir de enero de 1815, la Inquisición empezó a promulgar una serie de decretos en los cuales condenaba la Masonería y Fernando VII al recuperar el trono en 1824 desencadenó una nueva ola represiva contra los francmasones y los liberales que reclamaban una constitución. Más sorprendente es la presencia de la obra de Chateaubriand (quinto título), Le Génie du Christianisme (1802) ${ }^{27}$, cuya religiosidad cristiana no ofrece la menor sospecha. Quizás su presencia se justifique por la caída política de Chateaubriand en 1824. La sexta obra-Eudoxia, hija de Belisario ${ }^{28}$ - es de nuevo una obra de Montengón. La obra desarrolla un modelo de educación femenina «similar al que había forjado el filósofo ginebrino en sus obras pedagógicas» ${ }^{29}$ que se oponía al modelo tradicional controlado por la Iglesia. La obra siguiente -Cartas a Eugenia que «menciona en la $\mathrm{R}^{1}$ Orden»- atribuida al Barón de Holbach -Lettres à Eugénie, ou Préservatif contre les préjugés, 1768- fue traducida y publicada en París en 1810 por la imprenta de F. Didot con autoría, para burlar la censura, de Nicolas Fréret. El texto es una defensa del librepensamiento como lo testimonia la cita siguiente: «Si nous examinons sans préjugé la source d'une infinité de maux dans la société, nous verrons qu'ils sont dus aux spéculations fatales de la religion qui, enivrant les hommes d'enthousiasme, de fanatisme et de délire, les rendent aveugles, inconsidérés, ennemis d'eux-mêmes et des autres.» Belisario (el penúltimo título) corresponde a varias obras. Se pueden descartar la tragi-comedia del poeta y dramaturgo 
francés Jean de Rotrou (1609-1650) y la novela de Mme de Genlis publicada en 1808 sobre la que volveremos más adelante. La duda puede existir entre la obra de Victor-Joseph Étienne, apodado Étienne de Jouy (1742-1846) cuya tragedia Belisaire fue prohibida en 1818 y la más conocida novela de Jean François Marmontel, (1723-1799) ${ }^{30}$. La publicación de su novela en 1767 fue censurada por la Sorbona por defender la libertad religiosa y Mgr Christophe de Beaumont, arzobispo de París, redactó el 31 de enero de 1768 una condena de la obra para que fuese leída en las homilías de todas las iglesias de su archidiócesis. Los filósofos y en particular Voltaire salieron en su defensa: la polémica contribuyó al gran éxito europeo de la obra. Mme de Genlis se inspiró en la obra de Marmontel en su Bélisaire pero le dió un marcado carácter ideológico de defensa del espíritu religioso totalmente opuesto al librepensamiento de Marmontel. Concluye la lista de las obras censuradas de la librería de Juan Bergeon una «Historia abrebiada de la religión» que podría ser la del abad Charles François Lhomond (1727-1794) ${ }^{31}$, eclesiástico francés que rehusó la Constitución civil del clero de 1790. A priori la obra no parece ofrecer algo reprensible.

La librería de Cova con cuatro títulos cierra la lista. Volvemos a encontrar el Arte de amar de Ovidio ya presente en la librería de Martínez. Las «Poesías de Heredia» llevan el comentario siguiente: «Hay una obra de este tit ${ }^{\circ}$ impresa en Orléans $q^{e}$ es sediciosa». Poco probable es que se trate de las poesías del gran poeta santiaguero José María Heredia. (1803-1839) que tuvo que huir de Cuba a Estados Unidos en 1823 por sus vínculos con la Conspiración «Soles y Rayos de Bolívar». La primera edición de sus poesías tuvo lugar en Nueva York en 1825 y si la obra era conocida por unos cuantos amigos -por ejemplo se publica en Londres en 1825 en una revista un artículo titulado «Ocios de Españoles Emigrados» con una reseña positiva de las poesías de Heredia o también puede mencionarse una carta del pedagogo y poeta Alberto Lista (1775-1848) que en 1826 criticó positivamente los verso de Heredia ${ }^{32}$ - es improbable su difusión en Cuba en 1826. Por fin dos obras en francés -La liberté de la prensa (sic) y Existencia de Dios ${ }^{33}$ - confirman que la censura es política y religiosa. La libertad de la prensa no existió en el reinado de Fernando VII, a pesar de una tímida apertura en los últimos años. Podría tratarse de una obra de L. Hubert, que fue secretario de la Comisión de Censura del Ministerio del Interior francés y que publicó Sur la liberté de la presse en París en 1814, un pequeño opúsculo de 24 folios en octavo ${ }^{34}$. En cuanto a la Existencia de Dios, parece dudoso que se trate de la obra de Fénelon (1651-1715) -Démonstration de l'existence de Dieu, tirée de la connaissance de la Nature et proportionnée à la faible intelligence des plus simples- publicada en $1712 \mathrm{y}$ con numerososas reediciones a lo largo de los siglos XVIII y XIX.

En definitiva este análisis permite poner de realce algunas características importantes. La primera es la dificultad de identificación de los libros. Si en algunos casos queda bien clara, en muchos las dudas permanecen. Las consabidas técnicas utilizadas para burlar la censura tanto real como inquisitorial que consistían en la falsificación de títulos y de autores, en lugares de impresión inventados o falsos, etc. participan de esta dificultad. Siempre queda la duda de que tal obra no es la hoy día conocida sino otra de idéntico título pero de contenido inmoral, anticlerical o antirreligioso, liberal, etc. La segunda es que la censura se centra en tres dominios principales:

- el de la moral, en particular en su vertiente educativa (Cf. los obras de Montengón) pero también cuando lucha contra la literatura libertina o erótica (Arte de amar de Ovidio o sexualidad novelada de las religiosas) 
- el de la política desde la lucha contra la Ilustración, pasando por la censura del librepensamiento, del liberalismo, del constitucionalismo, de la libertad de prensa y la francmasonería

- el de la defensa de la ortodoxia católica

15 Cabe recordar que también la prohibición puede justificarse por la omisión de datos legalmente obligatorios como el pie de imprenta o las debidas licencias y aprobaciones. La tercera característica es que dominan las obras y los autores franceses desde los más conocidos como Marmontel o Holbach (que se puede considerar como francés a pesar de ser natural de Renania) hasta otros hoy día sepultados en el olvido como Drouyn de Bercy o Pigault-Lebrun. La última es que en algunos casos, más que una obra particular parece que se censura a un autor como Pigaul-Lebrun por ejemplo. Por fin, el mecanismo de esta censura revela los fallos de la censura en general : los libros ya estaban a la venta en las librerías lo que subraya la ineficacia del control de entradas de buques. Sin la excepcional Real Orden que mandó establecer listas de las obras presentes en la librerías habaneras, estas obras no hubieran sido retiradas de la venta. También evidencia que los libreros ignoran o fingen ignorar que las obras que venden están en índices reales o inquisitoriales de obras prohibidas, postura compartida por la inmensa mayoría de los libreros que se niegan a colaborar con la Inquisición y con la censura, por razones mayormente económicas. El fenómeno es bien documentado en Cádiz con «la dilación» de los libreros gaditanos ante la Inquisición que le pedía redactar listas periódicas de sus existencias $^{35}$.

\section{La presencia del libro francés en las librerías habaneras $^{36}$}

\section{Las características de las librerías}

16 Las listas de libros o catálogos manuscritos de La Habana ofrecen variantes en cuanto a su organización. En algunos, los libros vienen por orden alfabético mezclando títulos, autores e idiomas según la costumbre tan arraigada entre los libreros. En otros, los libros vienen presentados por idiomas y en muy pocos se vislumbra una clasificación temática pero no sistemática, por ejemplo se agrupan los diccionarios. En casi todos la descripción se limita al título, incompleto por lo general, a veces con el autor (muchas veces con peculiar ortografía cuando se trata de un autor extranjero); sólo en algunos casos se indica el número de tomos. Cuando se trata de obras en francés, incluso cuando la lista viene por separado indicando que son obras en francés, la norma es dar el título en español, lo que dificulta la identificación de las obras. Caso aparte lo constituye el catálogo de Juan Bergeon donde los títulos vienen en francés y que además termina su lista por una aclaración también en francés, cito: «plus quelques vieux bouquins incomplets et insignifians (sic)».

Los libreros habaneros ofrecen un total de 2407 títulos a los cuales podríamos añadir un promedio de 300 libros para cada uno de los catálogos extraviados (los de la librería del papel sellado, de Ramón Martínez y de Pascual Mendoza), con lo cual llegaríamos a unos 3300 títulos. Entre ellos, unos cuantos obras están presentes en muchas cuando no en todas las librerías, lo que reduce la variedad de títulos a unos 3000. La librería más pequeña es la de Pascual Mendoza con una oferta de solo 30 libros: el documento habla de un «almacen» lo que corresponde a un local donde el libro forma parte de un amplio 
abanico de mercancías a la venta, de un espacio no especializado. La librería de la Ymprenta de Gobierno y Capitania General tampoco es muy importante con sólo un total de 124 obras. De tamaño mediano son las de Bergeon y Petit con respetivamente 259 y 321 títulos. Las más importantes son las de Cova (378 títulos), Palmer (408 títulos), Minerva (419 títulos) y Ramos (438 títulos).

Examinaremos primero la oferta en su totalidad con en particular su repartición por idiomas tal como la refleja el cuadro a continuación. El $80 \%$ de estas obras están en castellano, pero sin embargo dentro de este conjunto, muchas obras son traducciones, en particular del francés. Los libros en francés totalizan un 16\%, más -entre 20 y $25 \%$ - si se toman en cuanta las traducciones. Es mucho, como mínimo, una de cada cinco obras es una obra francesa, lo que confirma la importante penetración del libro francés. La oferta confirma también la disminución muy importante del latín que apenas llega al $2 \%$ del total. Por fin, los libros en inglés ocupan un lugar comparable con el del latín, casi un $2 \%$ e incluso un poco más puesto que algunas obras inglesas circulan como traducciones francesas. En los catálogos no hay libros en idioma original italiano o portugués, pero si algunas traducciones.

Los libros en francés o traducidos del francés representan menos del $15 \%$ del total en las librerías de Cova (9\%), del Gobierno (10\%), de Palmer (10\%), de Petit (12\%) y de Ramos (13\%). En la de Minerva, totalizan un $40 \%$ que se desglosa de la manera siguiente: $22 \%$ de obras en francés y $18 \%$ de obras traducidas del francés. Dos librerías parecen especializadas en obras en francés : la de Mendoza con un 56\% y la de Bergeon con un $60 \%$. Si se sumaran las obras traducidas del francés, las cifras de estas dos librerías serían todavía más altas.

\begin{tabular}{|c|c|c|c|c|c|c|}
\hline Librería & Castellano & $\begin{array}{l}\text { Francés o traducidas del francés } \\
\text { (a) }\end{array}$ & Inglés & Latín & Total & $\begin{array}{l}\text { obras } \\
\text { francesas }\end{array}$ \\
\hline Cova & 371 & 38 & 17 & 6 & 419 & $9 \%$ \\
\hline Gobierno & 124 & 12 & & 5 & 124 & $10 \%$ \\
\hline Palmer & 368 & 40 & & & 408 & $10 \%$ \\
\hline Petit & 273 & 34 & & 14 & 321 & $12 \%$ \\
\hline Ramos & 369 & 55 & & 14 & 438 & $13 \%$ \\
\hline Minerva & 291 & $82(+66)$ & & 5 & 378 & $40 \%$ \\
\hline Mendoza & 30 & 17 & & & 30 & $56 \%$ \\
\hline Bergeon & 70 & 154 & 28 & 7 & 259 & $60 \%$ \\
\hline Total & 1910 & 401 & 45 & 51 & 2407 & $25,5 \%$ \\
\hline
\end{tabular}

(a) Las cifras en negrita corresponden a listas separadas por idiomas: francés, inglés o latín 
Por razones obvias, no podemos presentar aquí un análisis pormenorizado de los 2400 obras $^{37}$. El análisis tomará como base las tres listas de libros en francés que ofrecen las librerías de Minerva (82 títulos), de Bergeon (154 títulos) y de Ramos (55 títulos) a las cuales añadiremos los libros franceses (traducidos o no) presentes en el almacén de Pascual Mendoza (15 títulos) y las librerías de la Capitanía General (12 títulos) y de Cova (31 títulos) y también las traducciones de libros franceses presentes en la librería de Minerva: o sea un conjunto de 428 obras. La identificación precisa de los títulos de las demás librerías -Palmer y Petit- no se incluye porque está sin concluir. El cuadro siguiente sintetiza este recuento y revela que si en algunos casos el encabezamiento de listas («libros en francés, en castellano, etc.) o el idioma del propio título permiten saber si una obra es original o una traducción, en algunas listas es imposible saberlo.

\begin{tabular}{|l|l|l|l|}
\hline Titulos en & francés & traducidos del francés & en francés o traducidos del francés \\
\hline Bergeon & 158 & & \\
\hline Minerva & 82 & 66 & \\
\hline Cova & 1 & & 37 \\
\hline Mendoza & & & 17 \\
\hline Ramos & 55 & Sin estudiar & \\
\hline Ymprenta Gobierno & & & 12 \\
\hline Total & 296 & 66 & 66 \\
\hline
\end{tabular}

Este primer balance permite establecer una presencia notable del libro en idioma francés en torno al $10 \%$. A la par, también es evidente que las obras traducidas del francés son importantes (incluso a veces para traducir obras de otro idioma -inglés, italiano, portugués- se utiliza la traducción francesa en lugar de recurrir a la obra original) seguramente que cuando se concluya el estudio de todas las librerías, alcanzarán las obras de origen francés la tercera parte del total.

Un libro de cada diez libros presentes en las librerías estudiadas está en francés, lo que supone la presencia dentro del grupo de los lectores potenciales de un número bastante elevado de lectores capaces de leer directamente en francés. Los lectores que querían aprender el francés o profundizar sus conocimientos en este idioma, o simplemente tener a mano un diccionario de consulta, tenían un amplio abanico de ofertas ${ }^{38}$. La librería de Cova poseía una «Gramatica francesa», la de Ramos, dos -la de Cormon ${ }^{39}$ y la de Tellier ${ }^{40}-$, en realidad una versión de las múltiples ediciones de la Gramática de Charles François Lhomond $^{41}$ que entre el siglo XVIII y 1825 fue editada más de doscientas veces -y por fin en la librería de Bergeon, la Gramática de Chantreau ${ }^{42}$, que antes de ser profesor de historia en la Escuela Militar de Saint-Cyr había sido profesor de francés durante veinte años en España. Tampoco podía faltar la Gramatica Española y francesa de Sobrino ${ }^{43}$ que ofrecía la librería Minerva. Además de un «Vocabulario francés» en la librería de Minerva, el lector podía encontrar en la librería de Cova un buen surtido de diccionarios entre los cuales destacan un «Diccionario Latin Francés», un «Diccionario Ytaliano Francés» y el 
famoso Diccionario de Gattel ${ }^{44}$. La librería de Bergeon también completaba la oferta de diccionarios con el de Richelet que tuvo unas veinte ediciones entre 1680 y $1811^{45}$. Por fin, también podía aprovechar la presencia en la librería de Minerva del Arte de traducir de Capmany $^{46}$ que incluía una gramática con numerosos ejemplos de traducciones y un vocabulario, también con traducciones, de los idiotismos de la lengua francesa ${ }^{47}$.

\section{Las materias: visión de conjunto}

El cuadro siguiente presenta una primera aproximación al tema de las materias de los libros franceses.

\begin{tabular}{|l|l|l|l|l|l|}
\hline & Religion $^{48}$ & Derecho & Historia/geografia & Ciencias & Literatura/Gramáticas... \\
\hline Títulos & 89 & 2 & 70 & 82 & 172 \\
\hline$\%$ & 21,4 & 0,5 & 16,9 & 19,8 & 41,4 \\
\hline
\end{tabular}

Dominan con más del $40 \%$ las obras de literatura (puesto que dentro del conjunto las gramáticas, los diccionarios, etc. representan muy poco), la religión y las ciencias ocupan un lugar idéntico (en torno a los $20 \%$ ), la historia y la geografía un poco menos (17\%). El derecho casi no viene representado.

La distribución de las obras según las librerías permite dibujar una tipología de las estrategias de venta. Hemos visto como la presencia de obras en francés, o la importancia de las obras traducidas del francés, permitían elaborar una primera serie de distinciones entre las librerías. Del mismo modo, el peso relativo de las materias esboza otras estrategias comerciales, que también, en parte por lo menos, podrían reflejar distintas orientaciones político-religiosas de los libreros.

\begin{tabular}{|c|c|c|c|c|c|c|c|c|c|c|}
\hline & \multicolumn{2}{|c|}{ Religion } & \multicolumn{2}{|c|}{ Derecho } & \multicolumn{2}{|c|}{$\begin{array}{l}\text { Historia/ } \\
\text { geografia }\end{array}$} & \multicolumn{2}{|c|}{ Ciencias } & \multicolumn{2}{|c|}{$\begin{array}{l}\text { Literatura/ } \\
\text { Gramáticas... }\end{array}$} \\
\hline & Títulos & $\%$ & Títulos & $\%$ & Títulos & $\%$ & Títulos & $\%$ & Títulos & $\%$ \\
\hline Bergeon & 53 & 35,6 & 1 & 0,7 & 17 & 24,3 & 24 & 16,1 & 54 & 36,2 \\
\hline Minerva & 15 & 10,4 & & & 24 & 34,3 & 29 & 20,1 & 76 & 52,8 \\
\hline Cova & 8 & 21,1 & & & 4 & 5,7 & 11 & 28,9 & 15 & 39,5 \\
\hline Mendoza & 1 & 5,9 & & & 7 & 10,0 & 4 & 23,5 & 5 & 29,4 \\
\hline Ramos & 12 & 21,8 & 1 & 1,8 & 14 & 20,0 & 10 & 18,2 & 18 & 32,7 \\
\hline $\begin{array}{l}\text { Ymprenta } \\
\text { Gobierno }\end{array}$ & & & & & 4 & 5,7 & 4 & 50,0 & 4 & 50,0 \\
\hline Total & 89 & 21,4 & 2 & 0,5 & 70 & 16,9 & 82 & 19,8 & 172 & 41,4 \\
\hline
\end{tabular}


Quizás, el elemento más relevante sea la importancia de la literatura que en casi todas las librerías supera los $30 \%$ y en dos librerías representa la mitad de las existencias (Minerva con 52,8\% y Gobierno con 50\%): para los libreros habaneros ofrecer libros de literatura francesa es un buen negocio, y dicho de otro modo, existe un público importante de lectores de este tipo de obras. Las obras religiosas tienen una presencia muy diversa: nula (Ymprenta del Gobierno) o débil (Minerva con 10,4\% y Mendoza con 10,4\%), más importante con la cuarte parte (Cova, Ramos) e importante en la de Bergeon (35,6\%). La historia y la geografía no superan los $10 \%$ en tres librerías (Cova, Mendoza, Ymprenta), para las demás representan entre la cuarta y tercera parte (Bergeon, Ramos y Minerva). El peso de las ciencias es más homogéneo: todas entre el 15\% y 29\%, la de la Ymprenta siendo la excepción con un $50 \%$. No obstante, estas estrategias que son la de los libros franceses (traducidos o no) tendrían que ser matizadas por un idéntico análisis sobre la totalidad de las obras (en castellano, inglés, etc.).

Enfocaremos el estudio cualitativo de las materias centrándonos en solamente, por razones obvias de espacio, dos materias: los libros de religión y los libros de ciencias. Son dos sectores que ofrecen muchos contrastes. Los libros religiosos suelen ser rediciones de obras del siglo XVI o XVIII. Son obras, por lo general, tradicionales reservadas al clero (cuando se trata de obras especializadas) o leídas por los fieles. Las obras científicas suelen ser, en su inmensa mayoría, obras muy recientes, de las dos últimas décadas del XVIII y de los primeros veinte y cinco años del XIX. Además de un público profesional (médicos, etc.), eran leídas por todos los que querían mantenerse al tanto de los últimos descubrimientos y por los que generalmente tenían un espíritu menos conservador.

\section{Libros de religión}

28 Antes de analizar los libros de religión, nos detendremos sobre los dos únicos libros de derecho presentes. En la librería de Ramos, se vende un clásico de la literatura jurídica, la obra de Pufendorf publicada en 1672 sobre el derecho natural y de gentes ${ }^{49}$. La obra tuvo numerosas reediciones en latín y traducciones al francés ${ }^{50}$, italiano e inglés y fue objeto de debates en España y América. La segunda obra «Code de pólice» está en la librería de Bergeon. Son numerosas las obras con este título publicadas en la segunda mitad del siglo $\mathrm{XVIII}^{51}$. Quizás por ser más reciente sea el Code de simple police, à l'usage des juges de paix, commissaires de police, maires et adjoints por M. Boucher-d'Argis (Paris, B. Warée oncle, 1822, In- $8^{\circ}$, LVI-265 p.). Sin embargo la mayor parte de las obras de derecho son de autores españoles (y por eso no se incluyen en este análisis), es decir que en este dominio las influencias extranjeras y en particular francesas son menores.

Las obras francesas de religión totalizan 89 títulos. Analizaremos estas obras en función de las categorías siguientes: teología y defensa de la religión, oratoria, doctrina, hagiografía, espiritualidad, biblia y comentarios, liturgia y ars moriendi. La oratoria, con más de veinte títulos de sermones, discusos $\mathrm{u}$ oraciones fúnebres, ocupa un lugar destacado. Las obras de Bossuet (1627-1704) están presentes en cuatro librerías: sus Discursos escogidos en la de Ramos, sus Oraciones en la de Minerva y sus Sermones en la de Cova. En la librería de la Capitanía General sólo se menciona al autor Bossuet. Es imposible identificar estas obras por el número elevado de ediciones de sus obras oratorias (sermones, oraciones, etc.) que empiezan a publicarse a partir de 1772, incluso sus Obras completas ya se habían publicado en París, 20 volúmenes en 4 entre 1743 y 1753. A principios del siglo XIX, existen varias ediciones monumentales: hay una en Versalles 
de 43 volúmenes en $8^{\circ}$ publicada entre $1815-1819$ y otra parisina en 1825 de 60 volúmenes en $12^{\circ}$. La oratoria de Fléchier (1632-1710) se menciona cuatro veces: la librería de Minerva ofrece las Oraciones fúnebres ${ }^{52}$ así como la de Bergeon pero en francés, sus Sermones están en la de Cova, y sus Obras ${ }^{53}$ ( 3 tomos) en la de Ramos. De Massillon (1663-1742), otro famoso predicador, la librería de Bergeon tiene sus Sermons ${ }^{54}$, su Petit Carême y sus Sermons pour le Carême; la de Cova sus Sermones. Del jesuita Bourdaloue, la librería de Bergeon vende sus Sermons divers y la de Ramos un tomo de sus Discursos escogidos. Para completar la oferta de las obras de oratoria conviene mencionar al P. Roland Bourdon, agustino, de quien la librería Ramos posee unos Discursos escogidos ${ }^{55}$, los Sermones de Millot $^{56}$ (librería de Cova) y los Discursos escogidos de Fénelon y los de Fleury (ambos en la librería de Ramos). De Fleury también Ramos tiene a la venta una edición de sus Obras en 5 tomos y sus famosos Opúsculos también en cinco tomos ${ }^{57}$. Por fin algunas obras se mencionan únicamente por su título que corresponde a la oratoria, siendo sin embargo imposible conocer a sus autores. Son un Chef-d'œuvre oratoire y una Oraison funèbre, ambas en la librería de Bergeon. Este conjunto de obras se dirigían a miembros del clero para quienes podían servir de modelos en su labor misionera. La segunda mitad del siglo XVIII y las primeras décadas del XIX son un momento de gran reforma del arte de la predicación, reforma que se basa en la imitación de los grandes sermonarios franceses de tiempos de Luis $\mathrm{XIV}^{58}$. No obstante, estas obras también podían ser leídas por un público de fieles o de interesados por el arte del discurso-.

30 La segunda gran categoría de obras religiosas son las ediciones de la Biblia y sus exégesis o comentarios, es decir obras más bien reservadas a especialistas. Bergeon tiene tres biblias en francés: La Sainte Bible, la Bible de Royaumont y una Bible de Sacy incomplète. En realidad estas dos últimas obras son la misma también conocida como Bible de Port-Royal : L'HISTOIRE DU VIEUX ET DU NOUVEAU TESTAMENT, représentée avec des figures et des explications édifiantes tirées des Saints Pères pour régler les moeurs dans toutes sortes de conditions..(dite BIBLE DE ROYAUMONT). .... par feu M. Le Maistre de Sacy, sous le nom du sieur de Royaumont, prieur de Sombreval ${ }^{59}$. También posee la librería de Ramos una edición completa de esta biblia jansenista de Sacy en 25 tomos. Quizás sea la edición de Pierre Beaume, impresor librero en Nîmes, que la editó en 25 volúmenes entre 1780 y 1789, incluyendo la obra de Sacy, la de sus seguidores como el P. Calmet y unas concordancias. La última edición de la Biblia se encuentra en la librería de Minerva y es la de Jean-Baptiste Du Hamel (1624-1706) ${ }^{60}$ seguramente en latín. Algunas ediciones de partes de la Biblia completan estas Biblias. De Philippe Mezenguy (1677-1763), otro ilustre jansenista, los habaneros podían comprar el Compendio de la historia del antiguo testamento (en 10 tomos en la librería de Ramos) traducido al castellano por Don Francisco Mariano Nipho ${ }^{61}$. Del Nuevo Testamento, la librería de Bergeon proponía una edición en francés y la de Minerva una en español, ambas sin mención de autor. La de Bergeon proponía también un Pseaume de David, unas Epitres et évangiles y unas Parolles remarcables (sic) de l'évangile, todas sin autor asi como L'évangile médité que puede ser el de Bossuet ${ }^{62} \mathrm{o}$ el del P. B. Giraudeau corregida por el P. Duquesne ${ }^{63}$, obra con una decena de ediciones hasta 1818. La última obra de esta categoría es la Explicacion de los evangelios de César-Guillaume La Luzerne (1738-1821), obispo de Langres, en cinco volúmenes ${ }^{64}$ (librería de Ramos).

31 La doctrina es representada por cuatro catecismos: el famoso Catecismo histórico de Fleury ${ }^{65}$ (en castellano en las librerías de Cova y de Minerva y en francés en la de Bergeon) y el Catecismo de Pouget (librería de Cova). Se trata del célebre catecismo -también nombrado Catecismo de Montpellier- redactado por el P. François-Aimé Pouget en cumplimiento de la 
orden del sobrino de Colbert, Charles-Joachim Colbert de Croissy, jansenista y obispo de Montpellier. La vida de San Francisco de Sales (en francés y en español en librería de Bergeon) y una Vie des saints (Bergeon) son, con el Año cristiano del P. Jean Croiset (1656-1738), los textos de la categoría hagiografía. La edición de esta obra presente en los estantes de la librería de Minerva podría ser la edición traducida por el P. Isla ${ }^{66}$.

La librería de Bergeon tiene tres versiones de las «horas», es decir «El librito ù devocionario en que está el Oficio de Nuestra Señora, y otras devociones que rezan los Seglares $»^{67}$. Unas Heures nouvelles, unas Heures à la reine y unas Heures à la chancelière ${ }^{68}$. Bergeon también propone una serie de obras que podían servir tanto en momentos de oraciones privadas como en el de los oficios públicos: Formules de prières, Office divin, Paroissien romain, L'office de paques (sic) y Quinzaine de pâques. Esta presencia tan importante en la librería de Bergeon de obras religiosas en francés puede tener dos explicaciones complementarias: la existencia de un grupo de lectores cubanos capaces de leer las obras en francés (y se trata de un uso privado) o la celebración en iglesia de oficios en francés para la comunidad francesa presente en La Habana ${ }^{69}$. Cabe subrayar por fin la presencia de numerosos autores jansenistas.

El ascetismo, la religiosidad cotidiana, la espiritualidad y en algunos casos incluso la mera moral impregnada de religión constituyen una categoría que completa las horas y los diversos oficios que acabamos de mencionar. La librería de Bergeon sigue siendo la que tiene la mayor cantidad de obras de esta categoría con unos Exercices de piété, los Exercices de piété pour chaque mois de Honoré-Gaspard de Coriolis (1735?-1824) ${ }^{70}$, La journée du chrétien, Le chemin du ciel, una Histoire de la vertu, L'ange conducteur de Jacques Coret (1631-1721) $)^{71}$, Confrérie de St jean Baptiste ${ }^{72}$, unas Pensées chrétiennes y un Manuel du serviteur de Marie. En las librería de Cova y de Mendoza, el lector podía comprar un Arte de ser feliz ${ }^{73}$. Las comunidades religiosas podían adquirir el Retiro espiritual ${ }^{74}$ de Bourdaloue (librería de Minerva) y en su versión francesa en la de Bergeon. El lector que se interesaba por la misiones tenía en la librería de Minerva un Choix de lettres édifiantes de Jean-Baptiste Montmignon (1737-1824) ${ }^{75}$. La preparación a la buena muerte o ars moriendi tienen escasa representación con Le petit pensez-y-bien (librería de Bergeon) ${ }^{76}$. Se trata del libro titulado Pensez-y bien, ou Réflexions sur les quatre fins dernières. Nouvelle édition, augmentée d'un chapitre sur la dévotion à la Sainte Vierge, de plusieurs histoires édifiantes, de paroles remarquables et de prières durant la sainte messe, atribuido a Paul de Barry (1587-1661) o a Paul Le Clerc (1657-1740), obra editada en Aviñón por L. Aubanel en 1813 y de formato muy pequeño (en $18^{\circ}$ ). La primera edición es de 1737 y tuvo numerosas reediciones a lo largo del siglo XVIII.

La devoción a Cristo y a su Pasión vienen bien representadas con obras clásicas como la Imitación de Cristo de Kempis que tuvo un sinfín de ediciones pero también todo un amplio surtido desde los Colloques du calvaire de Noël Courbon ${ }^{77}$ hasta las Souffrances de Jésus del agustino portugués Tomás de Jesús (1529-1582) ${ }^{78}$ pasando por un Chemin de la croix, obras todas en la librería de Bergeon.

Por fin, la categoría de las obras de teología, de defensa del cristianismo o de apologética ofrece varios títulos. En la librería de Bergeon están las Vérités de la religión, los Fondemens (sic) de la foi, Les droits de la religion, las Démonstrations évangéliques, la Vraie idée du Saint Siège, y las Lettres de deux curés. Algunas son difíciles de identificar pero otras lo son menos. Las Pensées sur les plus importantes vérités de la religion et sur les principaux devoirs du christianisme, par un docteur en théologie son de Pierre Hubert Humbert (1687?-1778) ${ }^{79}$, y entre 1742 y 1825 se editaron unas veinte veces. Del abad italiano Pietro Tamburini 
(1737-1827) es la Vraie idée du Saint Siège, en 2 parties, ... Traduit de l'italien [par l'abbé G.-A. Jaubert] sur l'édition publiée à Milan en 1818. Las Lettres de deux curés des Cevènes sur la validité des mariages des protestants et sur leur exitence légale en France ... Par Gacon de Louancy, Londres 1779, siendo Gaston de Louancy un nombre que pudiera ocultar a un autor jansenista. En la librería de Minerva encontramos dos obras identificadas, la de Claude Pastoret (1755-1840), Moises considerado como legislador ${ }^{80}$ y la de Guillaume ClermontLodève, barón de Sainte-Croix (1746-1809): Misterios del paganismo traducida de la obra francesa Mémoires pour servir à l'histoire de la religion secrète des anciens peuples, ou Recherches historiques et critiques sur les mystères du paganisme, (Paris: Nyon l'aîné, 1744) que se reeditó cinco veces hasta los años treinta. Una Défense du clergé, única obra cuyo título viene en francés en el inventario de la librería de Cova puede completar esta lista. Caso aparte merecen la Obras de Jacques Saurin (1677-1730) en la librería de Minerva, por ser este autor, si se trata realmente de él, un predicador y pastor protestante ${ }^{81}$.

\section{Las ciencias}

\section{Matematicas, física y quimica} presente es Étienne Bézout (1730-1783). Fue examinador en escuelas militares (marina y artillería) para las cuales redactó una serie de cursos muy apreciados. Su Cours de mathématiques (1764-1769) tuvo varias ediciones. Lo encontramos en la librería de Minerva (Bezout), en la de Ramos (Aritmetica de Bezu) y en la de Cova (Matematicas de Bessut ). Elemens d'algèbre y Traité des équations ${ }^{83}$ (ambos en la librería de Bergeon) son títulos que corresponden a varios autores con numerosas ediciones en los siglos XVIII y XIX. Por fin quizá el Formulaire de prisme (librería de Bergeon) sea una obra de óptica.

La física cuenta con un mayor número de obras casi todos identificables salvo unas Leçons de phisique (sic) (librería de Bergeon). Dentro de las obras generales figuran el Diccionario de física de Brison y su Suplemento (ambas obras en la librería de la Capitanía General). Mathurin-Jacques Brisson (1723-1806) fue un naturalista y físico, profesor en varias instituciones y miembro de la Academia de Ciencias. Su Dictionnaire de physique (1780, $2 \mathrm{v}$. en $4^{\circ}$ ) fue reeditado y traducido al español ${ }^{84}$. La librería de Bergeon posee una obra clásica la Phisicae ${ }^{85}$ del físico holandés Pieter van Musschenbroek (1692-17601). Son seguramente sus Institutiones physicoe (1734), traducidas al francés en 1751. Las demás obras son textos para la formación de la juventud, plúbico muy importante para los libreros. Necesitaría el estudio de estas obras un capítulo aparte que postergamos para un trabajo más amplio. Los escolares y los estudiantes ${ }^{86}$ podían utilizar las Recreaciones físicas de Jean Castillon ${ }^{87}$ (librerías de Minerva y de Mendoza), las Cartas a Sofia sobre la fisica y química de LouisAimé Martin (librerías de Minerva y de Ramos), las Cartas de Leonhard Euler (librería de la Capitanía General) y el Testament de jerôme Sharp (librería de Bergeon). Jean-François Salvemini de Castillon (1708-1791) fue profesor de filosofía y de matemáticas en Utrecht, director de la clase de Matemáticas de la Academia de Berlín. Publicó una traducción de la Física de Locke (1761) y de la Aritmética universal de Newton (1774). Sus Recreaciones físicas fueron traducidas del francés por D. José Muñoz y Gaviria (Madrid: Mellado, 1863). También podría tratarse de la obra de Jean-Sébastien-Eugène Julia de Fontenelle, (1790-1842), Manuel de physique amusante, ou Nouvelles récréations physiques (Paris, Roret, 1826) dado que los manuales de la editorial Roret tenían gran popularidad en Cuba. LouisAimé Martin (1782-1847) fue un escritor francés cuya obra más conocida fue las Lettres à 
Sophie cuya segunda edición es de 1811 en París. También adoptando el género epistolar tan en boga en aquellas años, pero que arranca en el Humanismo, los escolares tenían a mano las Lettres à une Princesse d'Allemagne sur divers sujets de Physique et de Philosophie publicadas entere 1768 y 1772 por el matématico suizo Leonhard Paul Euler (1707-1783). Hay una edición en Berna por la Société typographique en 1778. Con el Testament de Jérôme Sharp, professeur de physique amusante... pour servir de complément à la «Magie blanche dévoilée», par M. Decremps (Paris, el autor, 1786, XIX-329 p., In-8) salimos de la física propiamente dicha para volver a un dominio también de moda en el siglo XIX, el de las fuerzas ocultas, del esoterismo. De químicos franceses, sólo la librería Minerva posee la Nouvelle nomenclature chimique, d'après la classification adoptée par M. Thénard de JosephBienaimé Caventou (1795-1877) ${ }^{88}$. J. L. Thénard, profesor de química en el Collège Royal de France, primer catédratico de química de la Facultad de Ciencias de la Universidad de París, publicó su famoso Traité de Chimie élémentaire, Théorique et Pratique en 1813.

\section{Ciencias de la naturaleza y astronomía}

Las obras más clásicas de esta materia son la de Georges-Louis Leclerc, conde de Buffon (1707-1788), presentes en las librerías de Minerva (Espiritu del Bufon) y de la Capitanía General (Obras de Bufon). Tuvieron numerosas ediciones tanto en español como en francés y estaban presentes en la casi totalidad de las bibliotecas de las élites. Dos diccionarios de historia natural completan la oferta: Diccionario de historia natural en la librería de Minerva y el Diccionario de historia natural aplicado a las artes, a la agricultura, a la economia rural y domestica, a la medicina en la librería de Ramos. Trátase de una obra monumental en 36 tomos con láminas publicada por la Société de naturalistes et d'agriculteurs en París, «Chez Deterville» en 1816. La librería de Ramos ofrecía las Lecciones de geología de la Metiere en tres tomos. Son las de Jean-Claude de La Métherie (1743-1817), uno de los primeros geólogos modernos. Sus Leçons de géologie se publicaron en tres tomos en 1816 en París. La antropología, por lo menos en uno de sus precursores más controverdidos, Julien Joseph Virey (1775-1846) está presente con su Tratado histórico y fisiológico completo sobre la generación, el hombre y la mujer donde propone la existencia de dos razas, la negra y la blanca. Fue traducido por Don Manuel Hurtado de Mendoza y publicado en Madrid, en la imprenta de Antonio Martínez, en 1821.

La astronomía ocupa un lugar notable con cuatro obras: una Histoire de l'astronomie y una Description de l'univers (ambas en la librería de Bergeon) difíciles de identificar puesto que varias obras con estos títulos se editan ente1700 et 1826. Bien conocidas son las Tablas de la lande (librería de Cova) -cuya primera edición parece ser de 1791- de Joseph Jérôme Lefrançois de Lalande (1732-1807), astrónomo francés. Publicó una edición corregida de las Tablas de Halley (1656-1742). También contribuyó con 250 artículos en la Enciclopedia de Diderot y d'Alembert.. La obra del marqués Marquis Pierre Simon de Laplace (1749-1827) es una buena síntesis de los trabajos de Newton, Halley, Clairaut, d'Alembert y Euler. La librería de Minerva vendía su Mécanique céleste publicada en cinco volúmenes entre 1798-1825.

\section{Economia, economia politica y agricultura}

No deja de sorprender la escasez de obras de agricultura (quizás esta primera sensación vendría desmentida por el estudio de las obras en castellano). La librería de Minerva ofrece un Curso de agricultura (no identificable por ser muchas las obras con semejante 
título) y la de Ramos El conservador de las abejas. Se trata de la obra de Jonas de Gelieu, Le Conservateur des abeilles, ou Moyens éprouvés pour conserver les ruches et pour les renouveler, publicado en París por Treuttel et Würtz en 1816.

Los interesados por la economía podían comprar las clásicas obras de Jean-Baptiste Say (1767-1832) en las librerías de Minerva y de Mendoza. Su Catéchisme d'économie politique, ou Instruction familière qui montre de quelle façon les richesses sont produites, distribuées et consommées dans la société impreso en París en 1815 por la imprenta de Crapelet tuvo numerosas reediciones (la segunda: Paris, Bossange père, 1821 y la tercera: Paris, AiméAndré, 1826$)^{89}$. La Riqueza de las naciones de Adam Smith publicada en 1776 y cuya primera traducción al francés es la edición en 4 volúmenes de La Haya (1778-1779) y al español de los años 90 está presente en la librería de Ramos. También se ofrecía una obra del italiano Saverio Scrafoni, Essai Sur Le Commerce General Des Nations de L'Europe traducida al francés en 1801 y al español en 1805 por Melchor Andarió y Castellvell (Madrid, Imprenta de la hija de Ibarra)(librería de Minerva). Otra obra en la misma librería no ha podido ser identificada: Economia Politica y moral de la Especie humana. Con el Traité du commerce presente en la librería de Bergeon se concluyen las obras teóricas de economía o economía política.

Mas, también las librerías habaneras ofrecían un buen surtido de obras prácticas, útiles para comerciantes o viajeros. Una obra importante son las Tablas de cambios por Martin en la librería de Ramos, también presentes con le título Régulateur universel en la de Bergeon. Les tables de Martin: ou Le régulateur universel des calculs en parties doubles ... pour trouver tous les rapports réciproques du nouveau système et des poids et mesures de tous les pays, ainsi que des francs, livres trounois et monnaies étrangères, Par C. F. Martin, Miembro de la Academia de Ciencias de París; se editaron en París, en casa del autor, en1817. Obra práctica era también el Secretario de Comerciantes (librería de Minerva) : Le Secrétaire du commerce, divisé en deux parties, contenant: $1^{\circ}$ la Législation commerciale avec les modèles des actes que les commerçants ont à faire... $2^{\circ}$ Les modèles de lettres, factures, mémoires, etc... Ouvrage utile à tous les marchands..., Paris, P. Blanchard, 1821. La librería de Bergeon ofrecía también obras útiles para los viajeros en su estancia en Francia como la "guía de las Postes impériales» y lo que más tarde se convertiría en un nombre común, el «Bottin». Se trata de Le Livre d'honneur de l'industrie française de Sébastien Bottin cuya primera parte se publicó en París, "au bureau de "l'Almanach du commerce"», en 1820. Cabe señalar también una obra de economía doméstica: La cocinera económica (librería de Bergeon) que podría ser La cocinera del campo y de la ciudad, ó Nueva cocinera económica / Traducida de la 51 edición francesa, y aumentada (Madrid: [s.n., s.a.], Tip. F. de P. Mellado...) que sería la traducción de La cuisinière de la campagne et de la ville ou nouvelle cuisine économique de Louis-Eustache Audot, obra que fue constantemente reedita a lo largo del siglo XIX. Sin ser propiamente dicho una obra de economía, pero por su carácter útil se añade en este apartado El Secretario del Gavinete (librería de Minerva), obra de Jean Puget de La Serre (1600-1665), Le Secrétaire du cabinet, ou la Manière d'écrire que l'on pratique à la cour, par le sieur de La Serre, obra del siglo XVII también constantemente reeditada o copiada.

\section{Medicina, farmacia, veterinaria}

La farmacia francesa viene representada por únicamente la Farmacia química de Simon Morelot (1751-1809) de la librería Ramos que sin duda es su Cours élémentaire théorique et pratique de pharmacie chimique ou Manuel du pharmacien-chimiste (Paris: Poignée, 1803, 2a ed. 1814). La librería de Bergeon ofrece una obra de veterinaria, una Anatomie des chevaux 
en 2 tomos. Una segunda obra de veterinaria es el Tratado de la vacuna (librería de Ramos) del Dr. Luigi Sacco, seguramente en su versión francesa: Traité de vaccination, avec des observations sur le javart et la variole des bêtes à corne, par le Dr Louis Sacco,... traduit de l'italien par M. Joseph Daquin (Chambéry, impr. de P. Cléaz, 1811) ${ }^{90}$. Obra moderna puesto que la primera vacuna fue utilizada en 1796 por Edward Jenner para luchar contra la viruela.

En cambio, la medicina reúne un número importante de obras. En primer lugar una serie de obras generales como la Opera medica de Sydenham (librería de Bergeon), el Examen de las doctrinas medicas de François Joseph Victor Broussais, el De medicina de Brown (ambos en la librería de Minerva). Thomas Sydenham (o Syndenham) (1624-1689), médico inglés, muy importante por ser uno de los padres fundadores de la medicina moderna; su Opera publicada en 1685 tuvo numerosas reediciones. El médico escocés John Brown (1735-1788), también forma parte de los que intentaron renovar la medicina con sus Elementa Medicinae (1780), obra traducida al francés por dos médicos franceses: el anatomista René-Joseph-Hyacinthe Bertin (1757-1828) y el médico Pierre Eloi Fouquier de Maissemy (1776-1850). Sin embargo, el más novedoso y radical es el médico y cirujano François Joseph Victor Broussais (1772-1838) cuyo Examen de la doctrine médicale généralement adoptée (1816) criticaba con fuerza las doctrinas antiguas y tuvo gran influencia.

Médicos y estudiantes podían adquirir dos tratados de anatomía en la librería de Minerva, el del famoso partero Jacques-Pierre Maygrier (1771-1835) -Manuel de l'anatomiste, ou Traité sur la manière de préparer toutes les parties de l'anatomie, suivie d'une description complète de ces mêmes parties, Paris, Éd. J.-S. Merlin, $1811^{91}$ - y el del no menos insigne fisiólogo Marie François Xavier Bichat, (1771-1802).- Anatomie générale appliquée à la physiologie et à la médecine, Paris, 1801, 4 volumes in- $8^{92}$. También podían comprar obras de fisiología como la de uno de los padres de la fisiología moderna François Magendie (1783-1855) con su Précis de physiologie (1816) cuya traducción se publicó en Barcelona ${ }^{93}$ o la de BalthasarAnthelme Richerand (1779-1840) cuyos Nouveaux éléments de physiologie publicados en 1801 tuvieron diez ediciones y traducciones a varios idiomas (ambas en la librería de Minerva) o también la de Charles-Louis Dumas (1765-1813). Principes de physiologie, ou Introduction à la science expérimentale, philosophique et médicale de l'homme vivant, Paris, Déterville, 1800-1803, 4 vol. in- $8^{\circ}$, con cuadros ${ }^{94}$ (librería de Cova).

Para estudiar las enfermedades en general, disponían de la Nosografía y terapéutica quirúrgicas de Richerand (librería de Minerva) cuya primera edición es de 1805-1806 ${ }^{95}$, de la obra más clásica pero que tuvo su importancia en el despertar de la medecina moderna, el Conspectus Therapiae generalis de Johann Juncker ${ }^{96}$ (1679-1759) publicado en 1736 (librería de Bergeon) y de una obra titulada «Maladie cronique» (sic) (ambas en la librería de Bergeon), difícil de identificar por ser su título demasiado genérico. También había obras que versaban sobre enfermedades peculiares. En la librería de Ramos, se vendía un Tratado de la tisis pulmonar que podría ser el de Joseph Raulin (1708-1784), uno de los médicos de Luis XIV -Traité de la Phtisie pulmonaire, avec la méthode curative et préservative de cette maladie, Paris, 1784, In-8- o el más reciente de Jean-Joseph Brieude (1729-1812), médico, agrónomo y geógrafo francés -Traité de la phtysie pulmonaire, 1803, Paris, 2 volumes. Bergeon ofrecía un Traité du scorbut ${ }^{97}$ que podría ser el del escocés James Lind (1716-1794), primer médico en haber estudiado de manera científica el escorbuto. Una vez más, una obra cuyo idioma original es el inglés llega a lectores cubanos a través de la traducción francesa llevada a cabo por dos médicos franceses: Jacques Savary, médico del rey, y Thomas Carrère (1714-1764), el primer médico en describir las aguas minerales en 
el Rosellón. De François-Emmanuel Fodéré (1764-1835), la librería Minerva proponía sus Leçons sur les épidémies et l'hygiène publique (Paris, Levrault, 1822-1824). Sobre el «morbo gálico» o «mal francés» la librería de Bergeon tenía el Recueil de l'affecteur. Se trata del Recueil de recherches et d'observations sur les différentes méthodes de traiter les maladies vénériennes et particulièrement sur les effets du remède connu sous le nom de rob antisyphilitique. Nouvelle édition augmentée d'un Traité sommaire des maladies vénériennes... par Laffecteur (Paris, l'auteur, 1810 ${ }^{98}$ ). El rob «Boyveau-Laffecteur» fue objeto de un largo debate y de una encuesta médica para probar su eficacia terapéutica, encuesta de la cual salió victorioso ${ }^{99}$. Asimismo era posible leer una obra importante sobre la alienación mental (librería de Cova); la de Philippe Pinel (1745-1826), médico que intentó humanizar el tratamiento de los enfermos luchando para que se les quitaran sus grillos: Traité médicophilosophique sur l'aliénation mentale ou La manie (París, 1800, con reediciones en 1801,1809). La odontología de un dentista francés del rey de España, Ricardo Le Preux ${ }^{100}$ está presente en la librería de Minerva con su Doctrina moderna para sangradores: en la qual se trata de la flebotomia y arterotomia, de la aplicacion de las ventosas, de las sanguijuelas, y de las enfermedades de la dentadura que obligan á sacar dientes, colmillos, ó muelas, con el arte de sacarlas (En Madrid: En la Oficina de D. Blas Román, 1788, 8º).

Otro grupo importante lo forman obras que tratan de las enfermedades de un grupo particular, sea por su edad (niños) sea por criterios socio-profesionales (marineros, campesinos, etc.). La librería de Cova ofrece un libro titulado Enfermedades de los niños y la de Bergeon uno sobre enfermedades de los artesanos (Maladies des artisans) y otra sobre enfermedades de los marineros, la de Louis Rouppe, médico de la marina holandesa, su De morbis navigantium.... (Leiden: Theodor Haak, 1764 ${ }^{101}$ ). La obra enciclopédica -Le Médecin du peuple, ou Traité complet des maladies dont le peuple est communément affecté, ouvrage composé avant la Révolution française de Louis Vitet (1736-1809) ${ }^{102}$ (impreso en Lyon: les frères Périsse, an XII-1804, 13 vol. in-12) -que proponía la librería de Bergeon corresponde también a esta categoría.

Por fin, algunas obras no son para especialistas sino obras de divulgación o que permitían la automedicación o la autocuración. Dos obras de este grupo podían ser compradas: el Mémorial de santé offert au public... por Vincent Fontanini (Lyon, 1809; librería de Bergeon) y el Avis au peuple sur sa santé, ou Traité des maladies les plus fréquentes, par M. Tissot,... Nouvelle édition, augmentée de la description et de la cure de plusieurs maladies, et principalement de celles qui demandent de prompts secours. Ouvrage composé en faveur des habitants de la campagne, du peuple des villes, et de tous ceux qui ne peuvent avoir facilement les conseils des médecins de Samuel Auguste André David Tissot, (1728-1797, librería de Minerva) ${ }^{103}$.

\section{Conclusiones provisionales}

Evidentemente, la visión que acabamos de dar de la oferta de libros de religión y de ciencias no corresponde a la realidad. Faltan por estudiar los libros españoles, o incluso ingleses. Falta también el estudio de las otras materias, en particular la literatura donde las obras francesas son numerosísimas. Sin embargo, el estudio confirma la presencia masiva de libros franceses (en francés o traducidos) en La Habana de principios del XIX. Confirma también la importancia del libro francés para acceder a obras de otros idiomas (inglés en particular) gracias a las traducciones al francés. Por otra parte revela la presencia de un amplio y diversificado público de lectores: especialistas y aficionados, escolares y profesores, hombres y mujeres, etc. También evidencia que los libreros 
habaneros utilizan toda una red de abastecimiento de libros procedentes de París que funciona muy bien (por lo demás, red que está sin estudiar en el caso cubano). Por fin, y quizás sea lo que diferencia fundamentalmente el comercio del libro en Cuba, e incluso para toda la América colonial, del comercio en España, es la ausencia de un fondo de libros antiguos. Las librerías españolas de fines del siglo XVIII y principios del siglo XIX solían tener un fondo de libros antiguos muy importante, y en muchos casos superior al de libros recientes. En La Habana parece que este fondo casi no existe (convendría comprobar si los libros españoles no modifican esta impresión) y que en su inmensa mayoría los libros son recientes, incluso cuando se trata de libros cuya primera edición es antigua. Las causas podrían ser en primer lugar la relativa escasez del libro en Cuba. Los libros que llegaban a Cuba permanecían en bibliotecas eclesiásticas o en bibliotecas privadas, algunos también, los de los funcionarios para quienes Cuba era una etapa en la carrera administrativa, volvían a España.

En segundo lugar, la imprenta cubana arranca muy tarde y no puede ensanchar de manera significativa el número de libros que circulan en la isla. Algo muy distinto de lo que ocurre en España, que sin tener la mejor imprente europea, tiene sin embargo una producción que empieza desde finales del siglo XV, sin hablar de las importaciones de libros extranjeros que de manera continua inundan la Península. Esta inmensa cantidad de libros, y aunque con el paso de los años muchos desaparezcan, termina formando millones de millones de ejemplares de los cuales una cuantiosa parte acaba en el mercado del libro antiguo ${ }^{104}$.

Por fin, hasta bien entrado el siglo XVIII, la librería cubana casi no existe. El comercio del libro tampoco puede aumentar esta cantidad de libros. Con el siglo XIX, las cosas cambian, y los libros llegan con mayor frecuencia y con mayores cantidades, pero son libros nuevos, libros nuevos que traen, no todos, ideas nuevas que la metrópoli, y cada vez menos, puede controlar. El Capitán General de Cuba, Francisco Dionisio Vives, como buen funcionario, cumple las órdenes del Rey, pero el intento de censura es de corto alcance y de poco sirve ante las nuevas armadas de libros franceses que durante un siglo, una tras otra, cruzarán el Mar Océano para una nueva Conquista de Cuba y de las antiguas colonias españolas.

\section{NOTAS}

1. Bernabé Bartolomé Martínez, «Las librerías e imprentas de los jesuitas (1540-1767): una aportación notable a la cultura española», Hispania Sacra, n 40, 1988, pp. 315-388.

2. Durante su mandato tuvo lugar la conspiración denominada "de los Soles de Bolívar», descubierta el 19 de agosto de 1823. Roque Garrigó, Historia documentada de la conspiración de los soles y Rayos de Bolivar, La Habana, Imprenta El Siglo XX, 1929.

3. Transcribimos los nombres de las librerías tal como vienen en el documento.

4. Marie-Claire Boscq, «L'implantation des libraires à Paris (1815-1848)», Le commerce de la librairie en France au XIX ${ }^{e}$ siècle : 1798-1914, Jean-Yves Mollier (Ed.), Paris, IMEC: Éditions de la Maison des Sciences de l'Homme, 1997, p. 27-50. 
5. Jesús Ruiz de Gordejuela Urquijo, La expulsión de los españoles de México y su destino incierto, 1821-1836, CSIC, Universidad de Sevilla, 2006, p. 45, n. 1.

6. Juana Zahar Vergara, Historia de las librerías de la ciudad de México. Evocación y presencia, México, UNAM, 2006.

7. Ambrosio Fornet, El libro en Cuba; siglos XVIII y XIX, La Habana, Editorial Letras Cubanas, 1994.

8. Ambrosio Fornet, op. cit., p. 21.

9. Ambrosio Fornet, op. cit., p. 13.

10. Ambrosio Fornet, op. cit., p. 21.

11. Ambrosio Fornet, op. cit., p. 112.

12. Quizás de la familia del impresor José Arazoza y Soler activo en 1820 (Examen crítico de las causas de la persecución que han experimentado los francmasones y esplicación [sic] de las Bulas de los sumos pontífices Clemente XII y Benedicto XIV, Habana: Oficina Arazoza y Soler..., 1820. Ambrosio Fornet señala la importancia de la familia Arazora en el mundo de los impresores entre 1813 y 1883 (op. cit., p. 214).

13. No debe confundirse esta librería con la actual Librería Minerva sita en la Calle Obispo y fundada en 1913 por Valentín García García.

14. Varios anuncios de impresos publicados en la prensa habanera de las primeras décadas del siglo XIX permiten localizar esta librería que se ubicaba donde se vendía el papel sellado.

15. Convento desafortunadamente demolido en 1957. El edificio tenía su fachada principal en la calle O'Reilly y daba a las calles de Mercaderes, Obispo y San Ignacio.

16. Ambrosio Fornet, op. cit., p. 38.

17. Así se califica a dos obras de la librería de Juan Bergeon.

18. Como lo indica el encabezamiento: «Lista de los libros $q^{e}$ se hallan venales en la Ymprenta de Gobierno y Capitania General la cual presento à la Secretaria de la misma consecuente a los decretos de Oficio publicados por orden del Exmo Sor Capitan General en los Diarios de la Habana ...».

19. Obra del jesuita italiano Giovanni Pietro Pinamonti cuya primera edición en español es La Religiosa en Soledad. Obra en que se expone a las religiosas el modo de emplearse con fruto en los Exercicios Espirituales de SanIgnacio de Loyola, y puede tambien servir a qualquiera Persona que desee reformar con estemedio su proprio Espíritu. Traducida en español por el Padre Martin Pérez de Culla, Barcelona, por Jayme Ossett y Carlos Sapera, Libreros, a costa de Francisco Suriá, Impressor, y de los dichos, s.a. (1755). 4 tomos.

20. Olga Portuondo Zúñiga, Inquisición versus Ilustración, http://www.sierramaestra.cu/aliansa\% $20 \mathrm{frances} /$ franciasantiago/sociedad/vinetainquisicion.htm

21. Obra que poseía en su biblioteca el abogado, científico y político liberal mexicano Melchor Ocampo.

22. Les Codes de l'Empire français de 1813 reúnen en un solo volumen los cinco códigos napoleónicos : el Code Napoléon (code civil 1804), el Code de procédure (1806), el Code de commerce (1807), el Code criminel y el Code pénal (1810).

23. Publicada en Murcia en 1774 por Francisco Benedito cuyo autor parece ser como consta en la censura del impreso: Agrícola de la Mère de Dieu.

24. Mi tio Tomás: ó sea el hijo natural de Rosalia la morena... / obra traducida del frances al Español, por A.P.Z.G., Madrid, 1823: Impr. de D. Eusebio Alvarez, $8^{\circ}$.

25. La obra fue secuestrada y censurada durante la Restauración francesa (1814-1830).

26. Sobre la francmasonería, son de útil consulta Aurelio Miranda y Álvarez, Historia documentada de la masonería en Cuba, La Habana, Molina y cía, Impresores, 1977 (1ª ed. De 1933); Félix Varela y Morales, «Sociedades secretas en la isla de Cuba», en Escritos Políticos, La Habana, Ed. de Ciencias Sociales, 1999, p. 122-129; Roger Fernández Callejas, Historia moderna de la Francmasonería en Cuba, La Habana, 1944 y Eduardo Moisés Torres Cuevas, Historia de la masonería cubana. Seis ensayos, La Habana, Imagen Contemporánea, 2006. 
27. La obra fue traducida al español: El genio del Cristianismo] / trad. del franc. al esp. por D.T.T. de l. R. , Madrid, 1806, 4 v.; 8ํㅡl mlla. La segunda edición es de 1818: Genio del Cristianismo, ó bellezas poéticas y morales de la religion cristiana... Nueva edicion aumentada con notas que forman el apéndice... Traduccion hecha libremente del francés por D. Torcuato Torio de la Riva, Madrid, por Ibarra, 4 v., 4 lám.; 8o y la tercera de 1825: Genio del Cristianismo ó Bellezas de la religion cristiana... / Nueva traduccion española ajustada á la séptima edicion del original francés por un C. del H.D.M. adornada con nueve laminas, Perpiñan, J. Alzine, $12^{\circ}$ mlla.

28. Eudoxia, hija de Belisario / por Don Pedro Montengon, Madrid, en casa de Sancha: se hallara en su Imprenta y Librería, 1793, 390 p., 8․․ Segunda edición en Barcelona por Juan Ignacio Jordi, 1815, 342 p., $16^{\circ}$.

29. Cita sacada de Gloria Angeles Franco Rubio «"Eudoxia. hija de Belisario” de Pedro Mentengón y la educación femenina en la España del siglo XVIII: la proyección literaria de una polémica», Arenal: Revista de historia de mujeres, Vol. 11, № 1, 2004 (Ejemplar dedicado a: La historia en la ficción literaria), pags. 59-89.

30. Traducida en español: Belisario traducido... por Dn. L.A.V., urdeos: Pedro Beaume, 1815, 276 p., 14 $\mathrm{cm}$.

31. Histoire abrégée de la Religion avant la venue de Jésus-Christ, Paris, 1791, in-12.

32. Estos datos provienen del prólogo de Elías Zerolo de la edición de 1892 de las Poesías lirícas de José María de Heredia.

33. El documento señala entre paréntesis «en francés».

34. La France littéraire, ou Dictionnaire bibliographique des savants ... de J. M. Quérard cuyo tomo cuatro se publicó en París en 1830, menciona este título.

35. Philip Deacon, «El espacio cladndestino del erotismo literario en la España dieciochesca», in M. Marieta Cantos Casenave (coord.), Redes y espacios de opinión pública: de la Ilustración al Romanticismo: Cádiz, América y Europa ante la Modernidad: 1750-1850, Universidad de Cádiz, Servicio de Publicaciones, 2006, p. 223.

36. Para establecer comparaciones ver Cristina Gómez Álvarez, «La transición entre los siglos XVIII y XIX: la difusión de las obras francesas en Nueva España», en Lise Andries y Laura Suárez de la Torre (coord.), Impressions du Mexique et de France/Impresiones de México y de Francia, Paris, Ed. de la Maison des sciences de l'homme, México, Instituo de Investigaciones Dr. José María Luis Mora, 2009, p. 45-63.

37. Dada la cantidad de informaciones que presentan los inventarios, estamos preparando un libro sobre el conjunto de estas librerías.

38. Son de útil consulta los trabajos sobre la traducción en los siglos XVIII y XIX: María Luisa Donaire Fernández, Francisco Lafarga (Ed.), Traducción y adaptación cultural: España-Francia, Servicio de Publicaciones, Universidad de Oviedo, 1991; Carmen Roig Morras, «Le discours idéologique véhiculé par les manuels de français en Espagne au XIX ${ }^{\mathrm{e}}$ siècle: quelques repères», en Marie-Christine Kok-Escalle, Francine Melka-Teichroew (Coord.), Changements politiques et statut des langues: histoire et épistémologie 1780-1945, Amsterdam, 2001.

39. J. L. Barthelemi Cormon, Gramática francesa, Lyon, $1810,8^{\circ}$.

40. Le Tellier, Charles-Constant (1768-1846), Grammaire françoise d'après Lhomond, à l'usage des lycées et institutions, par Charles-Constant Le Tellier,... 11e édition, Paris: Le Prieur, Belin, 1811, In-12, $212 \mathrm{p}$.

41. Lhomond, Charles François (1727-1794), Élémens de la grammaire françoise / par M. Lhomond, Paris : Colas, 1780, 1 vol. (IV-92 p.); in-12.

42. Pierre-Nicolas Chantreau (1741-1808), Arte de hablar bien francés, ó Gramática completa, Madrid, A. de Sancha, 1797, XX-343 p., $4^{\circ}$.

43. Gramática reeditada numerosas veces a lo largo del siglo XVIII, venía a menudo en los inventarios de bibliotecas privadas, por ser tan concocida, como «el Sobrino»; en la librería de Minerva aparace bajo la forma «El nuevo Sobrino o Gramatica Española y francesa». Una buena 
introducción al tema en Hans-Josef Niederehe, Bibliografía cronológica de la lingüistica, la gramática y la lexicografía del españo: Desde el año 1701 hasta el año 1800, Amsterdam \& Philadelphia, 2005.

44. Algunas ediciones: Gattel, Claude-Marie (Abbé), Nouveau dictionnaire de poche françoisespagnol, redigé d'après les meilleurs lexicographes... enrichi des conjugaisons des verbes espagnols,... par l'abbé Gattel,... - Nuevo diccionario portatil español y francés,... por lo abate Gattel, Paris: Bossange, Masson et Besson, 1798, deux parties en 1 vol. in- $8^{\circ} /$ Nuevo diccionario portatil español y francés... $2 a$ edicion enriquecida de los terminos de comercio y marina, aumentada de muchas voces omitidas en la 1a... por el abate Gattel,... - Nouveau dictionnaire de poche français-espagnol... 2e édition, enrichie des termes de commerce et de marine, augmentée.., Paris: Bossange, Masson et Besson, 1806, 2 parties en 1 vol. in-16/ Dictionnaire universel portatif de la langue française, avec la prononciation figurée, par M. Cl.-M. Gattel,... 2e édition, revue, corrigée et augmentée par l'auteur..., Lyon: Vve Buynand, 1813, 2 vol. in-8.

45. Richelet, Pierre (1626-1698), Dictionnaire françois, contenant les mots et les choses, plusieurs nouvelles remarques sur la langue françoise... avec les termes les plus connus des arts et des sciences..., Genève: J.-H. Widerhold, 1680, 2 parties en 1 vol. in- $4^{\circ}$.

46. Capmany y de Montpalau, Antonio de (1742-1813), Arte de traducir, ó vocabulario lógico y figurado de los modos de hablar del idioma Francés/ trad. á la construccion usual y frase genial de la lengua Castellana, Madrid, Imp. de D. Antonio de Sancha, 1776.

47. Brigitte Lépinette, «Traduction et idiotismes. El arte de traducir [...] (1776) de A. de Capmany (1742-1813): un texte influencé par l'Encyclopédie», Iberoromania, 1995, n 62, p. 28-54 / «El Nuevo diccionario francés-español de Antonio de Capmany», en Francisco Lafarga y otros, eds., La traducción: metodología, historia, literatura: ámbito hispanofrancés, Barcelona, PPU, p. 75-80[Actas del III Coloquio de la Asociación de Profesores de Filología Francesa de la Universidad Española).

48. La clasificación de materias retoma las cinco categorías establecidas por François Furet : «La "librairie" du royaume de France au XVIII" siècle», en Geneviève Bollème, Jean Ehrard, François Furet, Daniel Roche, et Jacques Roger, Livre et société dans la France du XVIII siècle, Paris et La Haye, Mouton, 1965-1970, 2 vol., I, 3-32.

49. Antonio Álvarez de Morales, «La difusión del derecho natural y de gentes europeo en la Universidad española de los siglos XVIII y XIX», en Vincent S. Olmos (coord.), Doctores y escolares: II Congreso Internacional de Historia de las Universidades Hispánicas, Valencia, 1995, Vol. 1, p. 49-59.

50. Pufendorf, Samuel von (1632-1694), Le droit de la nature et des gens, ou Système général des principes les plus importans de la morale, de la jurisprudence et de la politique traduit du latin de M. le baron de Pufendorf par Jean Barbeyrac, avec des notes du traducteur... et une préface, Amsterdam: G. Kuyper, 1706, 2 vol. in $-4^{\circ}$.

51. Por ejemplo: Du Chesne (teniente de policía en Vitry-en-Champagne), Code de la police, ou Analyse des règlemens de police..., Paris: Prault père, 1757 In-12, XLVIII-485 p.

52. El inventario menciona «brochées», o sea una edición en rústica.

53. La primera edición de sus obras es la de Ducreux en 1782. Constaba de 10 volúmenes en $8^{\circ}$. Se publican ediciones en español de sus sermones y/u oraciones a partir de los años 1770.

54. Conservamos el idioma (francés o español) de la mención del título en los inventarios.

55. El P. Bourdon consiguió su fama de orador en particular en su Discours funèbre sur la mort de Henry de Lorraine, duc de Mayenne, Paris, Bourriquant, 1621.

56. Parece dudoso que sean obras del abad Millot (1726-1785) que mientras fue abad fracasó en sus predicaciones, siendo después un buen redactor de textos de historia para la enseñanza.

57. Podría ser la edición de 1780-81 que constaba de 5 tomos.

58. El tema ha sido magistralmente tratado por Joël Saugnieux, Le jansénisme espagnol au XVIII siècle, ses composantes et ses sources, Oviedo, Textos y estudios del XVIII, 1976, y Les jansénistes et le renouveau de la prédication dans l'Espagne de la seconde moitié du XVIII siècle, Lyon, Presses Universitaires de Lyon, 1976. Importante es también el análisis de Mercedes Blanco, « Ambiguïtés d'une réforme: la critique de la prédiction conceptiste au XVIII siècle ", Mélanges de la Casa de Velázquez, 1988, Volume 24, n²4, p. 153-175. 
59. Como reza la edición de 1724, Paris, chez Moreau, in-4. Fue redactada en 1668.

60. Biblia sacra Vulgatce editionis, avec introduction, notes, tables chronologiques, historiques et géographiques, Paris, 1705.

61. Madrid: por Miguel Escribano se hallará en la librería de Correa, 1783, en $8^{\circ}$.

62. París, Pilout, (s. f.)e, en $8^{\circ}, 32$ pág.

63. L'Évangile médité et distribué pour tous les jours de l'année, Paris, C.-P. Berton, 1773, 12 vol., en $12^{\circ}$.

64. Explication des évangiles des dimanches et de quelques-unes des principales fêtes de l'année par Mgr l'évêque de Langres, Breslau: J. Kreuzer, 1800-1801, 5 vol., en $8^{\circ}$.

65. Catéchisme historique, contenant en abrégé l'histoire sainte et la doctrine chrétienne publicado en 1679 y puesto en el Índice.

66. Año christiano, ò Exercicios devotos para todos los dias del año: contiene la explicacion del mysterio ò la vida del santo... fielmente traducido del francès al castellano. En Madrid: en la imprenta de D. Antonio de Sancha. MDCCLXXVIII. A costa de la Real compañia de impresores, y libreros del reyno.

67. Definición del Diccionario de Autoridades, ed. facsímil, Madrid, Gredos, 1990, tomo II, D-Ñ.

68. Heures dédiées (à) Madame la chancelière, Paris: F. H. Muguet, 1717, en $12^{\circ}$. Hay otra edición más completa: Exercice spirituel, contenant la maniere d'employer toutes les heures du jour au service de Dieu Par V. C. P. Dedié à madame la chanceliere. Revû, corrigé, \& augmenté de nouveau, A Paris, chez Jacques Collombat imprimeur ordinaire du roy, \&c. ruë saint Jacques, au Pelican. M. DCC XIX. Avec approbation \& privilege du roy. Los autores (V. C. P.) serían Louis Cousin (1627-1707) y Paul Pellisson-Fontanier (1624-1693).

69. La presencia francesa es importante desde la sublevación en 1791de los esclavos en Santo Domingo. El caso mejor estudiado es el de Santiago de Cuba: Agnès Renault, La communauté française de Santiago de Cuba entre 1791 et 1825, Thèse de doctorat sous la direction d'Alain Yacou et Eric Wauters, Le Havre: Université du Havre, 2007, 2 vol., 888 p. Son de gran intérés también los trabajos de Gabriel Debien, de Jacques de Cauna, d'Alain Yacou y de María Elena Orozco-Lamore: La desruralización de Santiago de Cuba: Génesis de una ciudad moderna (1788-1868), Tesis de Doctorado, Departamento de Historia del Arte, Universidad de Oriente, 1994 y «El quartier français de Santiago de Cuba». Revolución y Cultura, 2004, nº 1, p. 11-18.

70. Exercices de piété, pour chaque jour, chaque semaine, chaque mois et chaque année... par l'abbé de Coriolis, Paris: T. Le Clerc, 1816, en $12^{\circ}$.

71. L'Ange conducteur dans la dévotion chrétienne, reduite en pratique en faveur des ames dévotes..., Liege, chez Jean-François Bassompierre, 1746, en $12^{\circ}$.

72. Podría tratarse de la Confrérie de Saint Jean-Baptiste, érigée en la paroisse de Saint-Denis de Saintines, diocèse de Beauvais..., Paris, imp. de A. Coniam, (s. d.). La imprenta de A.Coniam fue activa entre 1813 y 1829.

73. Moral rustica, arte de ser feliz en la tierra / trad. del frances al castellano por el Dr. D. Josef Castellnou, Madrid: Ofic. de D. Geronimo Ortega é hijos de Ibarra, 1791, en $8^{\circ}$; se trata de L'art d'être heureux sur la terre, mis à la portée du peuple de toutes les nations, Paris, de l'imprimerie de Ph.-D. Pierres, 1785 , en $8^{\circ}$.

74. Retiro Espiritual... para las Comunidades Religiosas / Escrito en frances por... y traducido en Español por otro Padre de la... Compañia [de Jesus], Segunda impresión, Madrid, Por Manuel Fernandez, 1736, en $8^{\circ}$. Hay otras ediciones en español en 1757,1760 y 1788 por lo menos. Es la traducción de la Retraite spirituelle à l'usage des communautés religieuses, Paris, 1721.

75. Choix des lettres édifiantes écrites des missions étrangères avec des additions, des notes critiques et des observations, Paris, Maradan, 1808-1809, 8 vol., en $8^{\circ}$; T. I-III. Missions de la Chine; T. IV. Missions de l'Inde; T. V-VI. Missions du Levant; T. VII-VIII. Missions de l'Amérique. Hay otra edición : Choix des lettres édifiantes, écrites des missions étrangères, précédé de tableaux géographiques, historiques, politiques, religieux et littéraires, des pays de mission. Seconde édition, augmentée d'une notice historique 
sur les missions étrangères, avec les actes des rois de France concernant les missions, de nouvelles lettres édifiantes et autres morceaux choisis, Paris: Grimbert, 1824-1826, 8 vol., en $8^{\circ}$.

76. Ofrece Bergeon tambien un Religioso moribundo sin identificar pero que podría corresponder a esta categoría.

77. Les Colloques du Calvaire, ou Méditations sur la Passion de N. S. Jésus-Christ,... par Monsieur Courbon, Paris, E. Michallet, 1693 , en $16^{\circ}$ (la quinta edición es de 1821).

78. Les Souffrances de Nostre Seigneur Jésus-Christ, ouvrage écrit en portugais par le P. Thomas de Jésus,... et traduit en françois par le P. G. Alleaume,... Nouvelle édition..., Toulouse, A. Manavit, 1811, 3 vol., en $12^{\circ}$.

79. Besançon: J.-C. Bogillot, 1742.

80. Moyse, considéré comme législateur et comme moraliste, par M. de Pastoret, conseiller de la Cour des Aides, de l'Académie des Inscriptions et Belles-lettres, de celles de Madrid, Florence, Cortone, etc., Paris: chez Buisson, Libraire, Hôtel de Coetlosquet, rue Hautefeuille, n² 20, 1788, In-8, 599 p., Sous le Privilège de l'Académie royale des Inscriptions et belles-lettres.

81. Sus obras son Sermons sur divers textes de l'Écriture Sainte (1708-1725) (impresos varias veces); Discours historiques, critiques, théologiques et moraux sur les évènements les plus mémorables de la Bible (1720-1728), Abrégé de théologie et de la morale chrétienne en forme de catéchisme (1722), États du Christianisme en France (1725-1727).

82. Una buena síntesis y la bibliografía en Luis Rico Romero, Alexander Maz Machado, Libros de texto de matemáticas en España durante los siglos XVIII y XIX, cumbia.ath.cx:591/pna/Archivos/ RicoL07-2927.PDF. También en Mariano Hormigón, Las matemáticas en el siglo XVIII, Madrid, EditorialAka,l Colección Historia de la ciencia y la técnica, 1994.

83. El Traité des équations podría ser la obra de Joseph-Louis Lagrange (1736-1813), Traité de la résolution des équations numériques de tous les degrés, Paris, 1808 , en $4^{\circ}$ que tuvo varias reediciones como en 1826 : Traité de la résolution des équations ... 3e édition conforme à celle de 1808 , et précédée d'une Analyse de l'ouvrage, par M. Poinsot, Paris, Bachelier.

84. Diccionario Universal de Física. Trad. al castellano y aumentado con los nuevos descubrimientos posteriores a su publicacion por los Doctores D. C. C. [Cristóbal Cladera] y D. F. X. C. Madrid, En la Imp. de Don Benito Cano, 1796-1802. 9 vols. 4. y Atlas.

85. Institutiones physicæ (1734), traducidas al francés en 1751.

86. El estudio más reciente y más completo sobre el tema es la Historia de la Educación en Cuba de Enrique Sosa Rodríguez y Alejandrina Penabad Félix, La Habana, ed. Bolaño, 1997- 200, tomos 1 a 8.

87. Nos parece que no puede tratarse por ser una edición antigua de la obra de Jacques Ozanam (1640-1717), Récréations mathématiques et physiques qui contiennent plusieurs problèmes d'arithmétique ... de géométrie, d'optique, de gnomonique, de cosmographie, de mécanique, de pyrotechnie et de physique. Avec un Traité nouveau des horloges élémentaires, Paris, J. Jombert, 1694.

88. Paris: Crochard, $1816, \mathrm{XVI}-298$ p. in-8.

89. La primera traducción al español podría ser la edicón parisina de Rosa (Cours du Palais Royl en París) fechada de 1822.

90. Hay otra edición: Paris: Michaud frères, 1813. $2^{\mathrm{e}}$ éd.

91. Existe una traducción: Nuevo manual de anatomia, ó tratado metódico y razonado sobre el modo de preparar todas las partes de la anatomía, seguido de una descripcion completa de estas mismas partes... Cuarta edición, revista, corregida y aumentada Trad. del Francés al Español, por don Manuel Hurtado de Mendox, Madrid, Imp. Calle de la Greda, 1820.

92. Obra traducida: Anatomía general aplicada á la fisiología y á la medicina [Texto impreso] / por Francisco Xavier Bichat; traducida del frances por Ramon Truxillo, Madrid, 1807-1814, Imprenta de la Hija de Ibarra. 
93. Compendio elemental de Fisiologia / Traducido del Frances al castellano, por D. Ramon Frau y D. Juan Trias, Barcelona, En la imprenta de la Viuda é Hijos de Don Antonio Brusi, 1828-29, 3 t. en 2 v.; $4^{\circ}$ +con tablas plegadas, al fin el tomo $1^{\circ} \mathrm{y}$ dos láms. al fin del tomo $3^{\circ}$.

94. Principios de Fisiologia ó introduccion á la ciencia experimental filosófica y médica del hombre vivo / Trad. del frances por D. Juan Vicente Carrasco, Madrid, M. Repulles, 1803-14, 4 v.; 4․

95. La traducción española es de 1822 y menciona que la versión francesa ya andaba por la quinta edición «traducido al castellano de la quinta edición», Madrid, Tomás Albán y Compañía, 1822, 14 láms. pleg.; $4^{\circ}$.

96. Aunque no se trate de una obra francesa, Juncker era alemán y la obra está en latín, la mencionamos porque completa la oferta médica.

97. Traité du scorbut... avec un tableau... de tout ce qui a paru sur ce sujet, traduit de l'anglois de M. Lind,... auquel on a joint la traduction du Traité du scorbut de Boerhaave, commenté par M. Van Swieten.., Paris, Méquignon, 1788, In-12.

98. Existen ediciones anteriores.

99. Para más detalles sobre el rob milagroso ver el artículo de Maurice Bouvet, Bulletin de la Société d'histoire de la Pharmacie, $\mathrm{n}^{\circ}$ 39, juin 1923: p. 264-272.

100. Dentista del siglo XVIII.

101. No se trata de una obra francés y el texto está en latín, pero completa la visión de las obras médicas extranjeras.

102. El índica aclara el contenido d ela obra y cual era el público destinatario: I-II. Maladies de la tête ; III. Maladies de la poitrine ; IV-V. Maladies du ventre ; VI. Maladies des voies urinaires ; VIIVIII. Des Fièvres ; IX. Maladies externes ; X. Maladies des parties de la génération ; XI. Maladies des femmes ; XII. Matière médicale : «Le Médecin du peuple. Matière médicale usuelle, ou exposition des médicamens et des préparations pharmaceutiques les plus efficaces»; XIII. «Aphorismes du médecin du peuple ou aphorismes du médecin de la montagne».

103. Lausanne: F. Grasset, 1761 (parece ser la primera edición), Paris: P.-F. Didot le jeune, 1762 (segunda edición francesa; hay varias ediciones españolas: Avisos al pueblo sobre su salud / por Mons. Tissot, $3^{\underline{a}}$ ed. original aumentada y firmada por el autor; la traduce en lengua castellana Don Joseph Fernández Rubio, 1773, Pamplona, Pasqual Ibañéz; Aviso al pueblo acerca de su salud, ó Tratado de las enfermedades unas frecuentes de las gentes del campo, $7^{\underline{a}}$ ed. correg. y aument. con un catecismo ó instrucción sobre las Asfixias ó muertes aparentes y socorros qe. conviene prestar, comp. por Mr. Gandarra; trad. por D. Jinan Galisteo y Xiorro, Madrid, José del Collado, 1815.

104. A este respecto, es de notar que la distinción entre librería de viejo y librería de libros nuevos no se establece realmente antes del siglo XIX.

\section{RESÚMENES}

Este artículo analiza los fondos de los libreros de La Habana en 1826. Ofrece una visión general de esos fondos y se centra en dos aspectos : la censura gubernativa y la oferta de libros franceses, en particular los libros de religión y los de ciencias.

Cet article analyse les fonds des libraires de La Havane en 1826. Il offre une vision générale de ces fonds et se centre sur deux aspects : la censure gouvernementale et l'offre des livres français, plus particulièrement des livres de religion et des livres scientifiques. 
The present article analyzes the funds of Havana booksellers in 1826. It offers a general vision of their funds and focuses upon two aspects: government censorship and the supply in French books, espacially in religious and scientific books.

\section{ÍNDICE}

Mots-clés: livres français, libraires, La Havane, XIXe siècle, censure

\section{AUTOR}

\section{JEAN-MARC BUIGUÈS}

Université Michel de Montaigne Bordeaux 